\title{
Using Group Storytelling to Recall Information in Emergency Response
}

\author{
Adriana S. Vivacqua and Marcos R.S. Borges \\ Department of Computer Science - Institute of Mathematics \\ Federal University of Rio de Janeiro \\ Rio de Janeiro, Brazil \\ avivacqua@dcc.ufrj.br; mborges@dcc.ufrj.br
}

\begin{abstract}
People and organizations frequently need to recall past events that, for some reason, were not documented when they occurred. The successful reconstitution of past events depends on several variables, such as whether key people are still available to tell what they know. This is especially true in emergency scenarios, where it is important to learn from past events in order to better prepare for future ones. In this paper, we describe a group storytelling approach to support knowledge acquisition from emergency respondents. This activity is supported by a groupware and yields a semi-structured account of past events, which can be later retrieved. We also present a case study with an actual emergency response team.
\end{abstract}

Keywords - knowledge management, group storytelling, emergency response

\section{INTRODUCTION}

Knowledge is an invaluable asset for an organization [6], and appropriate management of knowledge can make a big difference [7]. Organizations frequently need to recall past events that might not have been documented when they occurred. The successful reconstitution of past events depends on several variables, such as how long ago the event occurred, and whether key people are still available to tell their stories. Although it is sometimes difficult to restore all known events, an adequate recall process can make it easier for individuals to recollect facts and lead to a more accurate account.

Telling stories is a natural way of transmitting tacit knowledge among individuals, groups, and organizations. When a story is told, the author's intention is to transmit knowledge to the listener. Stories are great vehicles for wrapping together many elements of knowledge such as: explicit and tacit knowledge, information and emotion, the core and the context [1]. Stories are a very powerful way to represent complex, multi-dimensional concepts. While a certain amount of knowledge can be reflected as information, stories hold the key to unlocking the vital knowledge, which remains beyond the reach of codified information [2].

This is also the case in emergency management scenarios, where incident prevention plans must be drafted and continuously revised. Past events and experiences provide valuable input for plan revisions and new strategy formulation. However, this knowledge is present only in the heads of the individuals who participated in the incident response, who experienced the problems and may have new insight or suggestions as a result. This is usually a group of people, and hardly ever a sole individual, who must externalize their knowledge to provide useful input for incident prevention plans.

Knowledge recall is not a straightforward task: memory lapses may lead to incomplete information and the absence of key facts. Group storytelling can aid the recollection of events and lead to reflection. Reading each other's contributions may trigger individual memory or lead to discussion.

\section{GROUP STORYTELLING FOR KNOWLEDGE RECALL}

Knowledge exists both in the mind of employees and in documents. Many organizations assign high priority to documentation, but not all important knowledge is stored in documents [8]. The experience of the organization members, their ideas and decisions are also part of an organization's knowledge. These elements are known as tacit knowledge [9]: mental models, beliefs and ingrained perspectives not subject to easy manifestation. It is the opposite of explicit knowledge, which is simple to disseminate and share.

When we want to recall an episode that has occurred in the past and which has been witnessed by a group of people, we usually count on their testimony to reconstitute the episode. However, only when grouped together can the set of events start to make sense. This is achieved by knowledge exchange and combination. Although this is not enough to guarantee the full reconstitution of the episode - (e.g., some events may not have been witnessed), the collective knowledge produced by a group is usually better that a set of events reported by an individual. While telling a story, individuals may forget or disregard events they think are not relevant. There are also cases where faulty memory, subjective perception, partial or erroneous knowledge may distort the report [14].

Knowledge recall may be led by a person in role of editor, who interviews participants, interprets their views and stores 
the knowledge extracted in a repository. A second possibility, called group storytelling, is also guided by an editor, but reports are available for all participants to read. The advantage of this method is that the exposure of knowledge to all participants may stimulate the recall process.

Group storytelling is a technique that involves the construction and retrieval of stories in which more than one person contributes, synchronous or asynchronous, locally or in a distributed manner, through one or more media [3]. Knowledge generated by a group storytelling process is usually richer than that generated by the individual interviews [10]. The storytelling process discloses to the group different points of view, is stimulating and dynamic, and creates synergy among participants. The knowledge generated at the end of a collective recall process is a result of the combination of the knowledge of each participant about the event at hand.

Given appropriate technology, participants may be geographically distributed or work asynchronously, and still have the repository available as an extension of their memory.

\section{THE ROLE OF STORIES IN ACCIDENT PLANS}

The preparation of prevention plans depends on an analysis of incidents that have already occurred. While after the fact is easy to identify "heroes and villains", it is hard to imagine the pressure, dilemmas and uncertainties faced by respondents at the time decisions were made. The lack of historic information is the main obstacle to the creation of prevention policies. Managers are deprived of essential knowledge, information of vital importance to the deeper understanding of the incident.

A story of an incident usually contains uncertainties, gray areas and gaps. Subjective aspects, such as human emotion and cognition must be considered. Therefore, their perceptions of the incident must be retrieved. This is tacit knowledge, which is frequently hard to obtain.

Respondents work in teams and distribute tasks and information among themselves. Thus, knowledge of an incident is distributed among people involved in these events. One of the problems encountered when developing prevention plans is the recovery of collective tacit knowledge. To create an accurate account of events that happened, it would be useful to give a voice to the actors.

For that reason, we adopt a group storytelling technique to acquire stories of past incidents, to help the development of prevention plans. When members of a response team have the opportunity to talk and argue among themselves during the process of recounting the story, the resulting knowledge is enriched by the different views of each group member and the vision of the group as a whole. A facilitator participates to help the dynamics and has little interference in the process. The telling of the story is the responsibility of those best suited for this task: people involved in the incident.

\section{SUPPORTING GROUP STORYTELLING}

A description of an episode can be defined as a set of events and their relationships. This description falls into one of the three categories: the true version, the known version and the reported version. While reaching the true version depends on external facts, such as the set of events known and the proper establishment of the relationships, the difference between the reported and known versions is dependent on the knowledge recall process. The more people contribute, the higher the likelihood of completeness and accuracy, i.e., the closer the reported version is to the known version.

\section{A. Story Structure}

In order to be easily retrieved later, stories must be told in a certain way. We provide an underlying story structure to organize the knowledge it represents, creating a more constrained story telling activity but facilitating later retrieval.

A story can be divided into fragments, so the storyteller need not remember all the events and it is not essential that he or she has been directly involved in the incident [11] [5]. The storyteller has no obligation to tell the full story at once, this is done as events are remembered. Additionally, each fragment may be associated with other fragments.

Associations are a fundamental part of the structure of a story. They link fragments and may be of different types. In an incident account, it is necessary to show the relation of cause and effect, or that one event caused another. Associations that define the chronological sequence of events are also important, in order to provide a temporal view of the incident. Other associations help the task of building the story, because individuals are familiar with only a part of the story and the complete story can only be built through group interaction. The contradiction and gap associations are useful to indicate that some important information is missing between two fragments. Besides these, there should be "undefined" associations for those cases in which the participant feels none of the available types fits.

Should the facilitator feel the need, new categories may be added to the existing fragment descriptors and new types of associations. Stories are primarily encoded as textual fragments, but photos, audio and video may also be used.

\section{B. Computer Support}

Groupware facilitates several activities that are involved performed in group work, such as coordination, communication, awareness and level of collaboration. TellStory is in fact a set of web based applications that support the group storytelling metaphor. It implements categories of fragments and different forms of associations between pairs of fragments as previously described [13].

The tool allows a group to tell a story through the contributions of each one of the members. Any registered member of TellStory can create a story and invite new participants. An individual can participate in the story by performing one of the following roles:

- moderator: the person responsible for coordinating the actions inside of the story;

- user: contributor to the story;

- teller: the person that will write the final text;

- reviewer: the person who endorses the story; and, 
- commentator: the person responsible for identifying tacit knowledge externalization of the story.

In TellStory, each user can insert a fragment and categorize it according to the aforementioned categories. Possible actions during the construction of the story are: inclusion, edition, union, and division of fragments. Fragments can be introduced in random order and refined at a later stage. Figure 1 shows a flow of fragments in chronological order on the right.

A template guides the elaboration of the story using features of narrative structure. For example, it shows users that an event should always have a cause and effect relationship. It is also possible for users to define and configure characters, an activity which helps externalization. The template works as a guide for storytellers, stimulating their memories and helping them structure their thoughts. When the group understands and the story provides a large enough flow of events, the moderator can finalize the task. At this point, the storyteller writes a final text based on the sequence. The reviewer corrects casual mistakes and makes any changes to adjust the logic of the final text. Finally, the commentator searches for tacit elements that can be identified in the story, which are registered in the final text.

\section{V.CASE STUDY: FIRE AT THE SUPERMARKET}

Our goal with this study was to verify if group storytelling could indeed provide subsidies for the development of incident prevention plans. The event reported was a real fire at a Supermarket, which had happened within the past 6 months. Six team members who participated decisively in the response were selected to participate in the experiment, and one of them was assigned the role of facilitator. Participants had differing views of the event and could help each other in the construction of history.

At the end of the case study (when the facilitator decided to finalize the story), users answered a questionnaire. The experiment was conducted over eight days. The day before the beginning of the trial, we presented the goals of the experiment and the tool, and conducted a brief training session. After training, the construction of the story began, and all participants contributed to it either synchronously or asynchronously, aided by the facilitator.

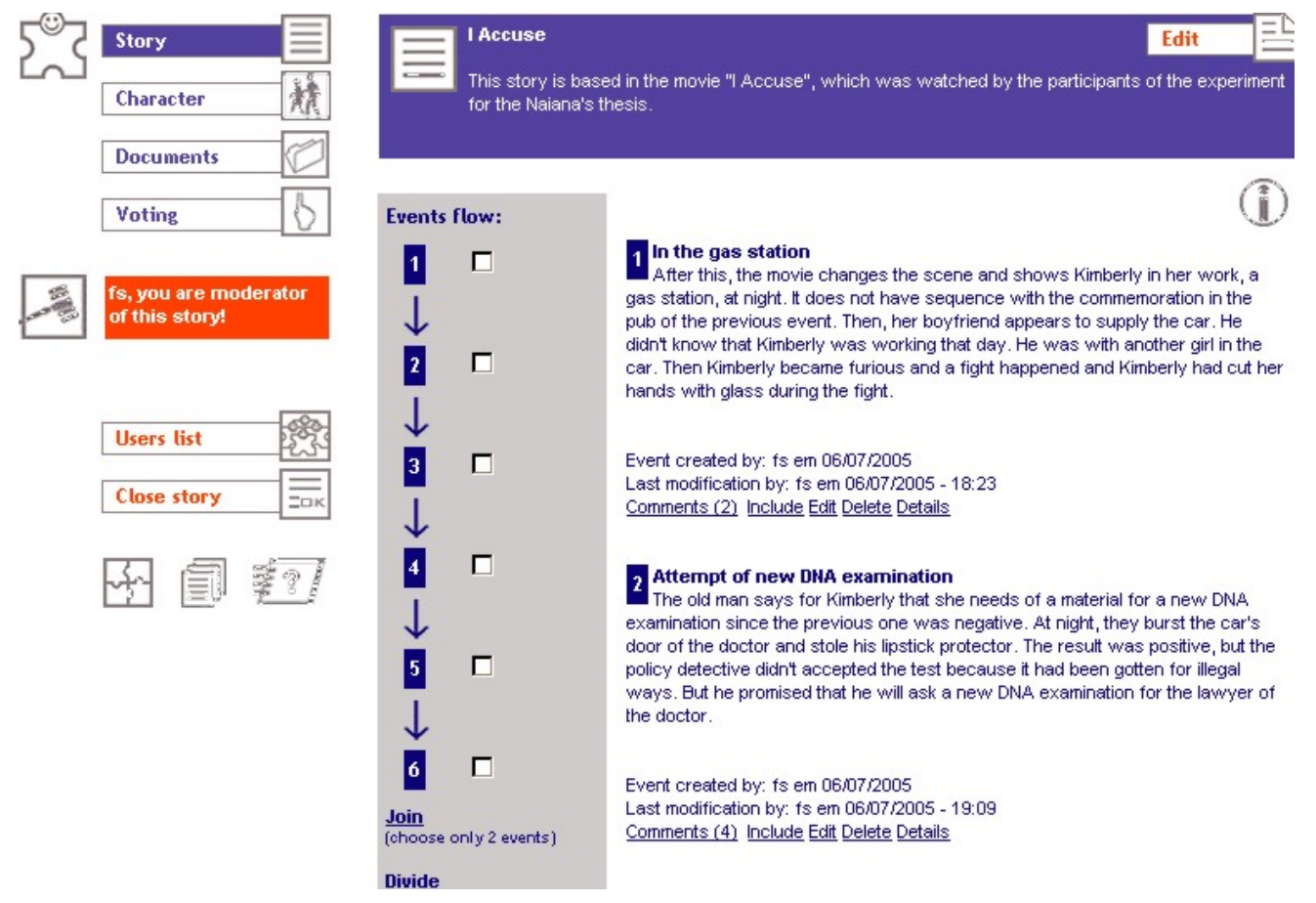

Figure 1 - Flow of a story (chronological view)

\section{A. Results and Analysis}

Officers of the Fire Department felt motivated to participate in the experiment and stated that watching each other's fragments helped them recall and question their own reports, as they looked at the problem for other points of view and perceived their colleagues' perspectives. The comments enriched the fragments created along with a description of the event. One participant reported: "One can tell through other participants', what went wrong, what went right and when”.

Fire brigade officials said that the stories told through the tool can help those responsible for drawing up prevention plans, as new data describing various views of the same event is added to the event, in addition to the experiences of each participant. This information promotes improvements in different aspects of the plan, with the eventual creation of a more comprehensive and efficient mode of operation for each type of event. They also stated it would be interesting to use these stories for training new firefighters and officers and for consultation and direct use by cadets and recruits, as they have little experience and few opportunities to go out on the field. 
Participants felt comfortable telling the story of the fire through the tool. However, if some of them had acted incorrectly during the event, he or she would be uncomfortable admitting to it in front of other colleagues, and especially before a superior. Therefore, a point criticized by most participants was the non-adoption of anonymity. The importance of the facilitator was also noted, which should motivate and mobilize the participants for the construction of history and prevent the escape of the group presented.

The story built during the experiment had 37 fragments and 08 associations. All types of fragment were used (description, fact and account), and the most frequent type was account, with 30 occurrences. Categories were uniformly used, except for artifact and hypothesis, which were not used. Regarding associations only completion, confirmation/compliance and temporal were used, to the detriment of cause/effect, denial/contradiction and gap associations. According to participants of the study, the tool could simplify the arrangement of fragments into topics through visualizations (using a graph or map), which would facilitate access and addition of new fragments.

The history recovered from the dynamics is filled with tacit knowledge that has now been externalized, which makes it very rich. Participants became aware of several pieces of information they had not been aware of before the experiment, thanks to their contributions and interactions. It is possible to identify aspects that can be exploited for the preparation of accident prevention plans. The following excerpts serve as examples of possible development of prevention plans:

"According to Lt. A (captain of Operations), it was difficult to control due to lack of fire hydrants in the area."

"This reinforces the importance of the hydrant-employee and of the hydrant search during periods of instruction to ensure successful fire extinction."

"My first attempt to fight the claim was without safety equipment, especially as regard clothes. Without approach masks and gloves, however, I found it very difficult to execute the mission. I came back equipped with masks and the captain loaned me his glove."

From the passages above, we can already imagine recommendations to be followed to eliminate or reduce the occurrence of similar accidents. For example: use of fire hydrants in the area, adoption of sprinklers, readiness measures, measures for reducing the strength of the fire; isolation of hazardous materials, and guaranteed access both for firefighting as for evacuation.

Thus, we find that group storytelling can in fact be useful in the elicitation of tacit knowledge, which in turn can be used to for incident prevention plans.

\section{CONCLUSIONS}

The application of the group storytelling technique shows that it is useful both for knowledge elicitation and that it can be adapted for particular domains, yielding useful results for the elaboration of incident prevention plans. Those involved in the incident will be able to record the experience close to the incident time and those responsible for drawing up prevention plans may in turn see a rich knowledge base of information that will help them build better plans.

The case study with the fire department showed that the technique actually helps in retrieval of knowledge and it is possible to extract relevant information from stories, constructed from the interaction of a group of people who were involved in an incident. An important contribution of this case study was the great synergy caused by the use of the tool. All officers of the Fire Department were pleased to externalize their knowledge and encouraged by the discoveries made.

As future work, we are considering the structures necessary for story creation by a large number of individuals. Contribution, revision and linking by large groups may lead to a very large number of fragments, which a sole editor would be unable to handle. Thus, new dynamics might be necessary to organize this process.

\section{REFERENCES}

[1] Sole, D.; Wilson, D.G. "Storytelling in Organizations: The power and traps of using stories to share knowledge in organizations". from LILA Harvard University Web Site: http://www.providersedge.com/docs/km_articles/Storytelling_in_Organi zations.pdf Accessed November 8, 2005.

[2] Ruggles, R., "The Role of Stories in Knowledge Management". Storytelling Foundation. Retrieved December 8, 2004, from LILA Harvard University Web Site: Available at: http://www.providersedge.com/docs/km_articles/The_Role_of_Stories_i n_KM.pdf

[3] Valle, C., Prinz, W., Borges, M.R.S.: Generation of Group Storytelling in Post-decision Implementation Process. Proceedings of the 7th International Conference on Computer Supported Cooperative Work in Design, Rio de Janeiro, Brazil (2002) 361-367

[4] Valle, C., Raybourn, E.M., Prinz, W., Borges, M.R.S.: Group Storytelling to Support Tacit Knowledge Externalization. Proceedings of the 10th International Conference on Human-Computer Interaction Vol. 4, Crete, Greece (2003) 1218-1222

[5] Perret, R., Borges, M.R.S., Santoro, F.M.: Applying Group Storytelling in Knowledge Management. Proceedings of the International Workshop on Groupware, San Carlos, Costa Rica, Lecture Notes in Computer Science, Vol. 3198. Springer-Verlag, Berlin Heidelberg New York (2004) 34-41

[6] Prusak, L.: Where did knowledge management come from?. IBM Systems Journal Vol. 40, No. 4 (2001) 1002-1007

[7] Alavi, M., Leidner, D.E.: Knowledge Management Systems: Issues, Challenges, and Benefits. Communications of the AIS Vol. 1, Article 7 (1999) 1-38

[8] Desouza, K.C.: Facilitating Tacit Knowledge Exchange. Communications of the ACM Vol. 46, No. 6 (2003) 85-88

[9] Nonaka, I. Takeuchi, H.: The Knowledge-Creating Company: How Japanese Companies Create the Dynamics of Innovation. Oxford University Press, Oxford, England (1995) 21-45

[10] Valacich, J.S., Dennis, A.R.and Connolly, T.: Idea generation in computer-based groups: A new ending to an old story. Organizational Behavior and Human Decision Processes Vol. 57, No. 3 (1994) 448-467

[11] Perret, R.: The group storytelling approach applied to knowledge management. M.Sc. Dissertation, Graduate Program in Informatics, Federal University of Rio de Janeiro, IM \&NCE (2004) (In Portuguese)

[12] Carminatti, N.: Group Storytelling Applied to Collective Knowledge Recall. M.Sc. Dissertation, Graduate Program in Informatics, Federal University of Rio de Janeiro, IM \&NCE (Forthcoming) (In Portuguese)

[13] Sikes, P.: 'Truth' and 'Lies' Revisited, British Educational Research Journal, Vol. 26, No. 2, 2000 